\title{
A traversing system to measure bottom boundary layer hydraulic properties
}

2

3

4

5

6

7

8

\author{
Ayub Ali ${ }^{*}$; and Charles J. Lemckert ${ }^{\dagger}$
}

Abstract: This study describes a new convenient and robust system developed to measure benthic boundary layer properties, with emphasis placed on the determination of bed shear stress and roughness height distribution within estuarine systems by using velocity measurements. This system consisted of a remotely operated motorised traverser that allowed a single ADV to collect data between 0 and $1 \mathrm{~m}$ above the bed. As a case study, we applied the proposed traversing system to investigate Bottom Boundary Layer (BBL) hydraulic properties within Coombabah Creek, Queensland, Australia. Four commonly-employed techniques: (1) Log-Profile (LP); (2) Reynolds Stress (RS); (3) Turbulent Kinetic Energy (TKE); and (4) Inertial Dissipation (ID) used to estimate bed shear stresses from velocity measurements were compared. Bed shear stresses estimated with these four methods agreed reasonably well; of these, the LP method was found to be most useful and reliable. Additionally, the LP method permits the calculation of roughness height, which the other three methods do not. An average value of bed shear stress of $0.46 \mathrm{~N} / \mathrm{m}^{2}$, roughness height of $4.3 \mathrm{~mm}$, and drag coefficient of 0.0054 were observed within Coombabah Creek. Results are consistent with that reported for several other silty bed estuaries.

* PhD candidate, Griffith School of Engineering, Griffith University Gold Coast Campus, Australia.email: a.ali@griffith.edu.au.

${ }^{\dagger}$ Associate Professor, Griffith School of Engineering, Griffith University Gold Coast Campus, Australia. email: c.lemckert@griffith.edu.au. 
1 Keywords: Bottom boundary layer; bed shear stress; roughness height; Coombabah Creek;

2 traverser.

\section{1. Introduction}

Estuaries are of immense importance to many communities. It has been estimated that 60 to 80 per cent of commercial marine fisheries resources depend on estuaries for part of or all of their life cycle (Klen, 2006). The flow and sediment transport patterns within estuaries are important as they play an important role in the functionality and health of these systems. Due to knowledge gaps, most numerical models used for predicting sediment transport (and related pollutant transport) rely on the use of approximations when determining bottom boundary conditions and sediment transport dynamics.

It is well recognised that the hydrodynamic properties of the Bottom Boundary Layer (BBL) affect sediment resuspension. The shear stress near the bed directly causes sediment erosion, affects vertical mixing, and relates to conditions conducive to sediment deposition. Therefore, to accurately predict and numerically model the flow and sediment transport patterns within estuarine systems, it is important to obtain detailed velocity data near the bed (Soulsby and Dyer, 1981).

It is very difficult to directly determine the bed shear stress in the field as its determination requires the measurement of forces very close to the bed, within the viscous sub-layer (see Figure 1) (Ackerman and Hoover, 2001). However, several indirect methods have been developed (see Section 3.1) that use more readily measurable velocity data to estimate bed shear stress. Previously, point source current meters, such as the S4 or Acoustic Doppler Velocimeter (ADV) (Jing and Ridd, 1996; Osborne and Boak, 1999; Stips et al., 1998, Gross et al., 1994; Black, 1998) have been used to derive BBL properties. However, in traditional fixed mooring 
1 arrangements they cannot usually fully resolve the boundary layer as they are restricted to a

2 single point measurement. Additionally, if a detailed boundary layer profile is to be determined,

3 then a number of devices must be deployed at one location (Gross and Nowell, 1983; Grant and

4 Madsen, 1986; Feddersen et al., 2007), which is usually beyond the scope of most researchers

5 due to the high cost of equipment and installation. More recently, Acoustic Doppler Current

6 Profilers (ADCPs) have been used to record velocity data near the bed (Cheng et al., 1999;

7 Thomsen, 1999), as they can provide near instantaneous three-dimensional velocity profile data

8 that can be used to estimate shear stress. However, ADCPs have limitations in that they have a

9 large $(>10 \mathrm{~cm})$ and wide spread (an order of one metre) sampling volume, and are unable to

10 sample close to the bed (approximately 10 per cent of the distance from the transducer to the

11 bed), which is the most important region for assessing BBL properties within shallow estuarine 12 systems.

13 In addition to the bed shear stress, the bed roughness is an essential parameter for 14 modelling current circulations, wave height attenuations and sediment transport within estuarine 15 and coastal waters - but it is often unknown and difficult to measure directly in the field. The 16 majority of modelling software packages (eg MIKE21/MIKE3 and ECOMSED) use an 17 estimated roughness height or a drag coefficient as an input parameter for describing the bed 18 shear stress in their sediment transport formulae (eg DHI, 2002; HydroQual, 2002). The physical 19 bed roughness generally consists of three roughness components: grain roughness, bedform 20 roughness, and sediment saltation roughness (You, 2005). The total roughness can be measured 21 from the affected velocity profiles using Prandtl's (1926) law of the wall equation, which would 22 substantially reduce the uncertainties of numerical models.

23 In this study, a new simple and robust system was developed to measure the flow 24 properties within estuarine BBLs. The system is based around a traversing mechanism used to 25 move an ADV vertically through the water column and, importantly, near the bed, so that 26 hydraulic properties of the BBL could be assessed. Additionally, bed shear stresses measured 
1 using four different methods were compared. Results of the successful application of this new system are presented in this paper through a case study of a shallow estuarine system.

\section{2. Theoretical Background}

The flow of water near a solid boundary has a distinct structure called a boundary layer.

6 An important aspect of a boundary layer is that the velocity of the fluid $(u)$ goes to zero at the 7 boundary. At some distance above the boundary the velocity reaches a constant value (Fig. 1)

8 called the free stream velocity $u_{\infty}$. Between the bed and the free stream, the velocity varies over 9 the vertical co-ordinate. The height of the boundary layer, $\delta$, is typically defined as the distance above the bed at which $u(\delta)=0.99 u_{\infty}$ (see Fig. 1) (Douglas et al., 1986).

The BBL can be subdivided into four regions (see Fig. 1): (i) viscous sub-layer (thickness $\delta_{v}$ ) representing a thin laminar flow layer just above the bottom - in this layer there is almost no turbulence and the viscous shear stress is constant; (ii) transition layer, where viscosity and turbulence are equally important and the flow is turbulent; (iii) turbulent logarithmic layer, where the viscous shear stress can be neglected and the turbulent shear stress is constant and equal to the bottom shear stress; and, (iv) turbulent outer layer, where velocities are almost constant because of the presence of large eddies, which produce strong mixing of the flow and shear stress gradually reducing to zero at the free stream (outer edge of the boundary layer). In a well-mixed fully developed turbulent flow over a rough channel bed, the outer turbulent layer covers approximately 80 per cent of the BBL thickness (Granger, 1985).

A typical phenomenon of turbulent flow is the fluctuation of velocity. The instantaneous velocity consists of a mean and a fluctuating component, and can be written as follows:

$$
U=u+u^{\prime}, \quad V=v+v^{\prime} \quad \text { and } \quad W=w+w^{\prime}
$$


1 where $U, V$ and $W$ are instantaneous velocities; $u, v$ and $w$ are time-averaged velocities; and $u$, $2 v^{\prime}$ and $w^{\prime}$ are instantaneous velocity fluctuations in longitudinal, transverse and vertical 3 directions, respectively. Shear stress in laminar flow is defined as:

4

$8 \quad \tau_{t}=\eta\left(\frac{d u}{d z}\right)^{2}$

where $\tau_{t}$ is the turbulent shear stress, and $\eta$ is a turbulent mixing coefficient (often called eddy viscosity). The eddy viscosity $\eta$ is not a property of the fluid like $\rho$ and $v$, but is a function of the velocity. Turbulent velocity fluctuations generate momentum fluxes resulting in shear stresses (called Reynolds stresses) between adjacent parts of a flow (Tennekes and Lumley, 1972). The Reynolds stress (turbulent shear stress) is defined as:

$$
\tau_{t}=-\rho \overline{u^{\prime} w^{\prime}}
$$

This can be measured with high precision velocity recording devices such as ADV and Laser Doppler Systems. Turbulence shear stress equals the bed shear stress when measured within the constant shear stress region (Fig. 1). profile (also known as von-Kármán - Prandtl equation) for the turbulent logarithmic layer as

$$
u(z)=\frac{u_{*}}{\kappa} \ln \left(\frac{z}{z_{0}}\right)
$$

21 where $u_{*}$ is the shear velocity defined as $u_{*}=\sqrt{\tau_{b} / \rho} ; \tau_{b}$ is the bed shear stress; $z_{0}$ is the 22 elevation where velocity is zero, usually known as roughness height; and $\kappa$ is the von-Kármán constant $=0.4$. Various expressions have been proposed for the velocity distribution within the 
1 transitional layer and the turbulent outer layer, none of which is widely accepted (Granger 1985;

2 Crowe et al., 2005). However, by modifying the mixing length assumption, the logarithmic

3 velocity profile also applies to the transitional layer and the turbulent outer layer. Under such

4 conditions, measurement and computed velocities show reasonable agreement. Therefore, we

5 have assumed a turbulent layer with the logarithmic velocity profile covers the transitional layer,

6 the turbulent logarithmic layer and the turbulent outer layer (Fig. 1). Once detailed velocity

7 measurement over a water column is available, the time-averaged velocities of the BBL can be

8 fitted to the logarithmic velocity profile (Eq. 5), and the unknown parameters (shear velocity and

9 roughness height) can be estimated. Furthermore, bed shear stresses can be estimated by using

10 several other methods utilising the velocity fluctuations (eg Kim et al., 2000; Pope et al., 2006).

\section{3. Methods and Materials}

\section{$12 \quad 3.1$ Techniques for estimating bed shear stress}

Commonly-employed techniques to estimate bed shear stress from velocity measurements include: (1) Log-Profile (LP); (2) Reynolds stress (RS); (3) Turbulent Kinetic Energy (TKE); and (4) Inertial Dissipation (ID) methods. The suitability, assumptions and limitations of these methods have been critically reviewed by Kim et al. (2000) and Pope et al. (2006). These authors concluded that the TKE approach was the most consistent and offered most promise for future development. However, they have suggested simultaneous use of several methods to estimate bed shear stress where possible, as all of these methods have both advantages and disadvantages; in this way, likely sources of errors can be identified.

The LP method fits velocity and height data into the von Kármán-Prandtl equation (Eq. 5) and estimates shear velocity and roughness height. The shear velocity is used to calculate bed shear stress from

$$
\tau_{b}=\rho u_{*}^{2}
$$


1 One of the main problems with this law of the wall approach (LP method) is that the theory is

2 strictly valid only for steady flows (Cheng et al., 1999; Pope et al., 2006). Another fundamental

3 feature of the LP method is that it is critically dependent upon precise knowledge of the

4 elevations above the bed at which the sequence of current velocities are measured (Kabir and

5 Torfs, 1992; Biron et al., 1998). While this may be straightforward for very smooth, fine-

6 grained, abiotic sediments, this can be considerably problematic in the case of natural estuarine

7 systems where grain size variation, bed forms and biota may conspire to increase bed roughness

8 and make precise determination of elevation less certain (Kabir and Torfs, 1992; Wilcock, 9 1996).

10 The RS approach (Eq. 4) may appear to represent a suitable method of estimating bed 11 shear stress for fully turbulent flow with a large Reynolds number (Dyer, 1986), and for cases where measurements close to the bed are available. However, it has been shown that this method may also be largely unsuitable in field or laboratory studies because of errors arising from any tilting of the velocity measuring device or to secondary flows (Kim et al., 2000). Moreover, the measurement must be within the turbulent logarithmic layer (constant stress region), and where density stratification is not important.

Turbulent Kinetic Energy (TKE) is the absolute intensity of velocity fluctuations from the mean velocity, ie the variances of the flow within an XYZ co-ordinate system, and is defined as:

$$
T K E=\frac{1}{2} \rho\left(\overline{u^{\prime 2}}+\overline{v^{\prime 2}}+\overline{w^{\prime 2}}\right)
$$

Simple relationships between $T K E$ and shear stress have been formulated in turbulence models (Galperin et al., 1988), while further studies (Soulsby and Dyer, 1981; Stapleton and Huntley, 1995) have shown the ratio of TKE to shear stress is constant, ie:

$$
\tau_{t}=C_{1} T K E
$$

24 The proportionality constant $C_{l}$ was found to be 0.20 (Soulsby and Dyer, 1981), while $C_{l}=0.19$ has been adopted by others (Soulsby, 1983; Stapleton and Huntley, 1995; Thompson et al., 
1 2003). The main advantage of the TKE method over the LP method is that it does not require

2 accurate knowledge of elevation above the bed, and is therefore less sensitive to conditions,

3 where sediment erosion and deposition can alter sediment levels by several millimetres or more.

4 Furthermore, in inter-tidal field studies some tilting of the acoustic sensor is almost inevitable,

5 and this method is less sensitive to tilting. However, there are some potential disadvantages to

6 the use of the TKE method. Firstly, the exact limits and dimensions of the sampling volume

7 must be known so when measurements are made within the BBL (near the bed) the sampling

8 volume is not mistakenly positioned partially within the bed (Finelli et al., 1999). Secondly, an

9 inherent feature of all Doppler-based backscatter systems is Doppler noise, which is attributable

10 to several sources, including positive and negative buoyancy of particles in the sampling

11 volume; small-scale turbulence (at scales less than that of the sampling volume); and acoustic

12 beam divergence, which in total may lead to high-biased estimates of turbulent energy from

13 Acoustic Doppler devices (Nikora and Goring, 1998). Finally, accelerating and decelerating

14 flows can cause errors in the TKE approach just as in the LP method. However, this may be

15 corrected by detrending the velocity time-series. Similarly to the second technique, the

16 measurement must be taken within the turbulent logarithmic layer. Bed shear stress can also be

17 estimated by using spectral analysis of turbulences and energy budgets.

18 For a log layer, a first-order balance between shear production $P$ and energy dissipation $\varepsilon$

19 is a fair assumption (eg Tennekes and Lumley, 1972; Nakagawa and Nezu, 1975)

$20-P+\varepsilon=\overline{u^{\prime} w^{\prime}} \frac{\partial u}{\partial z}+\varepsilon=0$

21 Taking $-\overline{u^{\prime} w^{\prime}}=u_{*}^{2}$ from the Reynolds stress method (Eq. 4) and $\frac{\partial u}{\partial z}=\frac{u_{*}}{\kappa z}$ from the LP method 22 (Eq. 5), we have:

$$
u_{*}=(\varepsilon \kappa z)^{1 / 3}
$$


1 The energy dissipation $\varepsilon$ can be estimated from the inertial sub-range of spectral density

2 distribution of the velocity (Grant and Madsen, 1986; Gross et al., 1994) measured at height $z$.

3 Then the shear velocity can be estimated from Equation (10).

Most importantly, all of these methods require the measurement to be made within the constant stress turbulent logarithmic layer. The aforementioned four techniques were used in this study to estimate bed shear stress from velocity data.

7

\section{$8 \quad 3.2$ Technique for estimating roughness height and drag coefficient}

While fluid flows over a solid surface, it encounters friction termed as bottom friction (or

bed roughness). The roughness height $z_{0}$ is most often estimated from recorded velocity profiles

11 (Eq. 5) while bed shear stresses can be computed using velocities at different points in the water 12 column and the heights of those points with reference to the bed. The velocities and corresponding elevations measured from a water column are plotted onto a logarithmic graph, and roughness height $z_{0}$ and shear velocity are obtained from curve fitting (Wilkinson, 1986; Bergeron and Abrahams, 1992; Ke et al., 1994; Mathisen and Madsen, 1996).

The drag coefficient is also used to represent the bed roughness in numerical models. The

17 drag coefficient $C_{D}$ (at a referenced height $z_{r}$ ) can be calculated using roughness height $\mathrm{z}_{0}$ (Gross et al., 1999; and Bricker et al., 2005) from:

$$
C_{D}=\left[\frac{\kappa}{\ln \left(z_{r} / z_{0}\right)}\right]^{2}
$$

which depends upon bed sediment grain size and bed-form geometry. Therefore, the roughness height and drag coefficient can be estimated from the traverser-collected velocity profiles. 


\section{$1 \quad 3.3$ New traversing system}

\section{$2 \quad 3.3 .1$ Instrument set-up}

In order to easily and readily measure velocities within the BBL, a new traversing system comprising a flexible head ADV (Vector velocimeter; Nortek AS), an altimeter (Tritech Digital Precision Altimeter; model PA500/6-S; Tritech International Ltd), and a DC underwater motor (model P00625, Seaeye Marine Ltd.) was assembled on a tripod (see Fig. 2). The tripod was made from hollow (to reduce weight) and thin (to minimise the flow blocking effect) aluminium pipe. Along one leg of the tripod, a track was fitted along which a small cart ran. The ADV probe and the altimeter were attached to the cart, which was moved along the track using the motor (fitted on top of the tripod). Expendable wooden plates were also fitted under the legs to prevent the tripod from sinking into the ground. The ADV measured the water velocity (mean and turbulent components), while the altimeter determined the height of the sampling point above the bed. The ADV was connected to a laptop computer for the purposes of controlling and data logging. To reduce any blocking effects, the ADV sensor head was kept $120 \mathrm{~mm}$ away from the leg. The altimeter provided a 0-5VDC analogue signal, which was calibrated against the height and read directly into the ADV, thus ensuring simultaneous height and velocity measurement. The traversing motor was operated using an external 12VDC power supply and control cable.

The altimeter was attached vertically in a support frame on the cart and $120 \mathrm{~mm}$ away from a tripod leg (Figure 3). The ADV probe head was set $106 \mathrm{~mm}$ in front of the altimeter. Nortek (2004), the manufacturer of this ADV, reported the presence of weak spots close to the boundary where velocity data might be problematic. Initially the ADV was set up vertically looking downward; however, in this configuration the velocity data were found to be very noisy between 50 and $200 \mathrm{~mm}$ above the bed. To reduce the thickness of the problematic layer and to get closer to the bed, after testing various angles, a $45^{\circ}$ inclination of the ADV head-unit with 
1 the vertical was selected. The sampling volume was $180 \mathrm{~mm}$ below the altimeter and $100 \mathrm{~mm}$

2 away from the ADV transducer. The main housing of the ADV in addition to its external battery

3 housing was placed on a pipe screwed to the remaining two legs (see Figure 2). This helped to

4 keep the ADV sensors pointing upstream when the instrument was lowered into the water

5 column, thus minimising the frame blocking effect. Furthermore, data were only collected when

6 the flow was approaching towards the frame.

A special multi-cable was made to configure the instrumentation and view the data online.

8 This consisted of four sub-cables, including: (1) an 8-pin cable connected to the ADV; (2) a 6-

9 pin cable connected to the altimeter; (3) a 3-pin cable connected to the underwater external

10 battery (see Figure 2) for supplying power to the ADV and to the altimeter, and (4) an 8-pin data

11 I/O cable connecting to the laptop on the boat.

12 Overall, it was found the system can be used to measure the hydrodynamic properties at

13 different heights up to one metre from the bed with the accuracy of elevation of $\pm 2 \mathrm{~mm}$ and the 14 accuracy of velocity of $\pm 0.5 \%$ of the measured value.

\subsubsection{Study site}

The traversing system was tested and used within Coombabah Creek (Fig. 3), which is a

1817 km long, moderately impacted (Cox and Moss, 1999; Lee et al., 2006; Dunn et al, 2007;

19 Benfer et al., 2007) sub-tropical tidal creek. The creek catchment (area $44 \mathrm{~km}^{2}$ ) is urbanised with residential, commercial and light industrial developments. It flows through Coombabah Lake and ultimately discharges into the Gold Coast Broadwater, a vitally important coastal system both economically and recreationally within southern Moreton Bay, Queensland, Australia.

23 Coombabah Creek's northern bank is lined with mangroves, whilst most of its southern bank is 24 lined with concrete and rock walls belonging to residential developments. The lower section of 25 the creek has an average width of approximately $100 \mathrm{~m}$ and an average depth of $4 \mathrm{~m}$, with 
1 relatively steep banks on its southern side and only a few exposed sand banks at low tide.

2 However, the upper section is approximately $200 \mathrm{~m}$ wide, with an average depth of $1 \mathrm{~m}$ and 3 many exposed sand/mud banks at low tide. Episodically large inputs of freshwater occur during 4 periods of heavy rainfall, predominantly during summer periods. Benfer et al. (2007) reported 5 that Coombabah Creek developed inverse estuary characteristics during the summer months 6 when rainfall events did not occur.

7

\subsubsection{Altimeter calibration}

As mentioned previously, a critical aspect of velocity profile measurements within the

$\mathrm{BBL}$ is an accurate knowledge of the heights at which the velocity measurements are made. For

this reason an altimeter was incorporated into the traversing system. The altimeter was calibrated in a laboratory tank where we could readily and accurately measure distances. Altimeter signals (read and logged as counts by the ADV) were calibrated in the lab against the height within a water tank, and the following relationship was found:

$$
a=0.16 b-59.72
$$

16 where $a$ is the height of altimeter above the bed ( $\mathrm{mm})$ and $b$ is the measured altimeter signal

17 (count), with a correlation coefficient $\left(R^{2}\right)$ of 0.99 . The count $(b)$ was the mean of two minute

18 altimeter signals at a constant height $(a)$ with $1 \mathrm{~Hz}$ frequency, while the height was measured

19 manually with a scale ruler. The mean standard deviation of the altimeter signals was 13 counts

20 (equivalent to $2 \mathrm{~mm}$ of altimeter height). The minimum height the altimeter could measure was

$21150 \mathrm{~mm}$, a high level of noise was evident when the height was $<100 \mathrm{~mm}$; this limitation was a

22 consequence of the operational nature of the altimeter. To overcome this problem on the 23 traverser, the altimeter was set $>180 \mathrm{~mm}$ from the bed at the lowest traverser height. 


\section{$1 \quad$ 3.3.4 Field measurement}

After the set-up was fully tested, the traversing system was taken and deployed within Coombabah Creek, Gold Coast Broadwater (Australia) for field measurements (see Figure 4). Measurements covered a full range of ebb current during a spring tide. The mean water depth was $2.5 \mathrm{~m}$. Velocities were measured from at least five elevations above the bed, with more measurements near the bottom. Data were also collected while moving the cart up and down, with an average speed of $2.0 \mathrm{~cm} / \mathrm{s}$ throughout the full traverser range, together with the point measurements. Six profiles were measured with 30 min intervals taking $\sim 20$ minutes to complete a single profiling cycle. A profiling cycle consists of following steps:

Step 1: Lower the traverser into the water column;

Step 2: Align ADV probe along the streamline (pointing upstream);

Step 3: Move ADV to a desired elevation;

Step 4: Record data for two minutes;

Step 5: Move ADV to a new elevation;

Step 6: Repeat steps 4 to 5 at least 5 times to complete a profile;

Step 7: Move ADV to the lowest/ highest point;

Step 8: Continue moving ADV up/down up to its limit;

Step 9: Repeat steps 7 to 8 in opposite direction.

This sampling routine permitted analyses of the different BBL property determining techniques.

\subsection{Data processing}

Initially, raw ADV data were processed using ExploreV software supplied with Nortek ADV systems (Version 1.55 Pro, Nortek AS). This software was used to rotate the measured velocity from $\mathrm{XYZ}$ co-ordinate system to stream-wise, transverse and vertical co-ordinate systems. The preset $45^{\circ}$ inclination angle and ADV recorded heading, pitch and roll data were used to rotate the measured data. The direction of the main stream flow was measured at the site 
1 with a hand-held compass. Velocity data having a correlation score $<70$, or Signal Noise Ratio

$2(\mathrm{SNR})<5$, or velocity greater than three times their standard deviation were counted as a bad

3 data. Less than $5 \%$ of all measurements were of sub-standard quality, and so were removed from

4 further processing. Stationary ADV data were used to calculate mean velocities, variances,

5 stresses and energy dissipation rates for the measurement points. These calculated parameters

6 were then utilised in estimating the bed shear stresses by using four different methods.

The four distinct methods described earlier in this paper were used to calculate the bed shear stresses with stationary ADV data. The mean velocities and their elevations were fitted into the logarithmic profile (Eq. 5); and shear velocity and roughness height were estimated for each profile (see Fig. 5a). Some points measured within the weak spots or outside of the logarithmic layer were excluded from the log profile; however, at least four points were used for a profile. Next, the shear velocity was used to calculate bed shear stress using Equation (6). The estimated roughness height $z_{0}$ was used in Equation (11) to calculate drag coefficient and the standard height of one metre was used as the reference height in this equation.

Turbulent shear stresses at various heights were estimated using Equations (4), (7) and (8). Energy dissipation rates (along with their heights) were used in Equation (10) to estimate the shear velocity, $u_{*}$. Estimated shear velocity was then used in Equation (6) to calculate the bed shear stresses.

Therefore, the RS and the TKE methods provided shear stresses at different heights, and the shear stress in the constant stress layer was considered as the bed shear stress. On the other hand, the ID and the LP methods provided bed shear stresses directly. stress and roughness height; and subsequently drag coefficient. After removing the sub-standard data, velocities and elevations were fitted into Equation (5), similar to stationary ADV data (Figure 5b) and; shear velocity and roughness height were estimated. The estimated roughness height $z_{0}$ was used in Equation (11) to calculate drag coefficient. 


\section{4. Results and Discussion}

3 Three sets of velocity and height data were measured for each profiling cycle: (1) keeping 4 the ADV probe stationary at different heights; (2) moving the ADV probe upward; and (3)

5 moving the ADV probe downward; to fit with the logarithmic profile. The flow properties were 6 assumed to be steady during a profiling cycle, as it took a maximum of 20 minutes to complete 7 the profiling cycle. Hence there are three sets of bed shear stress, roughness height and drag 8 coefficient data available for each profiling cycle (Fig. 6). Tide levels during the measurements 9 are also shown on Fig. 6 for the same time frame. Figure 6 shows that the bed shear stress follows the trend of the mean velocity; that is, high bed shear stresses during high flows and low

11 bed shear stresses during low flows. Bed shear stress varied in the range of $0.43 \mathrm{~N} / \mathrm{m}^{2}$ to 0.56 $12 \mathrm{~N} / \mathrm{m}^{2}$ for velocities from $0.20 \mathrm{~m} / \mathrm{s}$ to $0.25 \mathrm{~m} / \mathrm{s}$. Results are fairly consistent with that reported by 13 Cheng et al. (1999) for South San Francisco Bay; Kim et al. (2000) for York River Estuary; and Sherwood et al. (2006) for Grays Harbor in Washington (silty bed estuaries). It can be seen that variations in bed roughness heights and drag coefficients are very small during the measurement period, which implies there was no significant change of bed material and bed forms during the ebb tide measurement period. Similar mean velocity, bed shear stress, roughness height and drag coefficient estimates were derived for stationary and moving ADV data. Turbulent shear stresses at different elevations (except within weak spots) were determined using stationary ADV data, and are presented in Fig. 7(a). On the other hand, bed shear stresses estimated from dissipated energy recorded at various heights are shown in Fig. 7(b) with referenced heights. A brief summary of bed shear stresses estimated by all four methods are given in Table 1. It can be seen from Fig. 7(a) that the shear stresses from both the Reynolds stress and the TKE methods produced very similar shear stress variations. The highest shear stress was considered to be the bed shear stress; this was approximately $0.48 \mathrm{~N} / \mathrm{m}^{2}$, and was 
1 observed at a height of about $160 \mathrm{~mm}$ above the bed. It then gradually reduced to about 0.20

$2 \mathrm{~N} / \mathrm{m}^{2}$ at a height of $1000 \mathrm{~mm}$ above the bed. Available shear stresses below $160 \mathrm{~mm}$ showed a

3 drastic reduction to one-fifth of the maximum value at about $20 \mathrm{~mm}$ above the bed. Bed shear

4 stresses determined by the ID method (Fig. 7(b)) provided quite similar values, with the average

5 value being slightly lower than that from the LP method.

6 The approximate height and thickness of flow layers during the study period were deduced

7 from turbulent shear stress profiles (see Fig. 7(a)). The turbulent outer layer was observed to

8 start from approximately $160 \mathrm{~mm}$ above the bed, and extended beyond the measured layer. On

9 the other hand, the thickness of the viscous sub-layer was less than $20 \mathrm{~mm}$, since turbulence was

10 still present at the lowest recorded height $(20 \mathrm{~mm})$. We measured velocity data at least at one

11 point from the constant stress layer (turbulent shear stress was maximum, and quite similar to the

12 bed shear stress derived from the LP method) and observed that the constant shear stress layer

13 extended up to $160 \mathrm{~mm}$ from the bed. It is vital to precisely locate the turbulent logarithmic layer

14 in estimating bed shear stress with the Reynolds stress and the TKE methods in the absence of

15 the vertical profile.

16 In summary, all four methods produced similar shear stress estimates. The mean bed shear

17 stress estimated by the LP method was the highest $\left(0.49 \mathrm{~N} / \mathrm{m}^{2}\right)$, followed by the TKE $(0.48$

$\left.18 \mathrm{~N} / \mathrm{m}^{2}\right)$ and the Reynolds stress $\left(0.46 \mathrm{~N} / \mathrm{m}^{2}\right)$ methods. On the other hand, the estimated value

19 derived by the ID method was the lowest $\left(0.39 \mathrm{~N} / \mathrm{m}^{2}\right)$. However, the variations are not large, and

20 all shear stress estimates are within the error bands. The LP method produced quite similar bed

21 shear stresses $\left(\right.$ Std. $0.06 \mathrm{~N} / \mathrm{m}^{2}$ ) from all profiles, while the Reynolds stress method produced a

22 more scattered value (Std. $0.12 \mathrm{~N} / \mathrm{m}^{2}$ ). Therefore, the LP method was the most consistent

23 method in relation to the ID, TKE and Reynolds stress methods.

24 The errors related to the shear velocity calculated from the logarithmic profile were 25 estimated using Gross and Nowell (1983) formula: 
$1 \quad \operatorname{err}=\left(t_{\alpha / 2, n-2}\right)\left[\frac{1}{n-2}\left(\frac{1-R^{2}}{R^{2}}\right)\right]^{1 / 2}$

2 where $t$ is the Student's $t$ distribution for (1- $\alpha)$ confidence interval with $n$ - 2 degrees of freedom.

3 Here $n$ is the number of measurement points, and $R$ is the regression correlation coefficient. An

4 average error of $\pm 30 \%$ with $95 \%$ confidence level was observed in shear velocity estimation.

5 Moreover, Yu and Tan (2006) observed more than 3\% difference of bed shear stress for $1 \mathrm{~mm}$ of

6 error in height of near bed data.

7

The standard errors of the shear stresses estimated using the Reynolds stress method was

9 estimated using the following Sherwood et al. (2006) formula:

$$
e_{u w}^{2}=\frac{1}{N}\left[1+\frac{C_{u u} C_{w w}}{C_{u w}^{2}}\right]
$$

11 where $C_{u u}$ and $C_{w w}$ are autocovariances of u' and w'; $C_{u w}$ is covariance of u' and w'; $N$ is the degrees of freedom, equal to the number of statistically independent realisations of the 13 turbulence field (Soulsby, 1980; Bendat and Piersol, 1986), which was estimated as:

$14 \quad N=\frac{|U| T}{l}=\frac{|U| n}{z f_{s}}$

where $T$ is the sampling period and is equal to $\mathrm{n} / \mathrm{f}_{\mathrm{s}}$, where $n$ is the number of samples $(=3840)$; and $f_{s}$ is the sampling frequency $(32 \mathrm{~Hz}) ; l$ is the turbulence length scale, which scales with $z$, measurement elevation; and $|U|$ is the mean speed. The mean standard error was $0.05(10 \%$ of the bed shear stress), with a $95 \%$ confidence interval of 0.09 . Standard error of bed shear stress measured by ID method was estimated at various heights (see Fig. 6(b)) using statistical formula and an average error was observed $\pm 35 \%$, with a $95 \%$ confidence limit. In the case of TKE,

21 Garcia et al. (2006) predicted $26 \%$ of standard error from 32 sets of synthetic turbulent signal, 22 which was validated with 80 sets of laboratory data. In addition to the statistical errors, there are several other sources of errors that were not determined in this study such as errors due to 
1 physical constraints of instrument (eg Doppler noise) and experimental set-up (eg tilting). In

2 conclusion, all methods provided quite a similar value of bed shear stresses in view of associated 3 error ranges.

A few limitations to this system were observed from this study: (1) the velocity data 5 between elevations of 50 and $150 \mathrm{~mm}$ above the bed were noisy due to weak spots (Nortek, 6 2004), although this data can be used in the LP method as the mean values were unaffected; (2)

7 velocity very near the bed was underestimated when the ADV sample volume partially 8 penetrated into the bed, as reported by other studies (this data was not analysed here); (3)

9 maximum traversing range of a metre may not be enough to cover the full boundary layer under 10 all conditions; and (4) a relatively flat bed is essential for the best system stability. Future 11 developments aim to fully automate the system to add a 2nd ADV so that, once deployed, the system can operate over a full tidal cycle.

\section{5. Conclusions}

This article described a new underwater traversing system that made estimation of bed shear stress and roughness height robust, and best use of all available techniques at the same

17 time. The LP method was found to be the easiest and most useful, followed by the ID, TKE and 18 RS methods for estimating bed shear stress within shallow estuaries and rivers. More importantly, the LP method estimated both bed shear stress and roughness height, both essential parameters for sediment (or pollutant) transport modelling at the same time, whereas the other three methods estimated only bed shear stress. Moreover, the other three methods require precise velocity measurement within the constant stress layer (within centimetres) near the bottom to determine the bed shear stress. Mean velocity (after filtering noise) within the weak spot appeared reasonably accurate, and therefore was used in constructing the velocity profile. However, the same data could not be used for calculating turbulent shear stress due to the noise. 


\section{Acknowledgement}

3 The authors would like to acknowledge the financial assistance of the Cooperative

4 Research Centre for Coastal Zone, Estuary and Waterway Management. Acknowledgments are

5 also made to Mr Johann Gustafson and the lab technicians for their assistance in making the

6 traverser and collecting data from field with this system. Acknowledgements are also made to Dr

7 M. Maraqa, Dr M. H. Azam, Dr M. F. Karim, and Mr Ryan Dunn for their suggestions on 8 improving the manuscript.

\section{References}

11 Ackerman, J.D. and Hoover, T.M., 2001. Measurement of local bed shear stress in streams using a Preston-static tube. Limnology and Oceanography, 46(8), 2080-2087.

13 Benfer, N.P., King, B.A. and Lemckert, C.J. 2007. Salinity observations in a subtropical estuarine system on the Gold Coast, Australia. Journal of Coastal Research, SI 50, 646 651.

Bergeron, N.E., and Abrahams, A.D., 1992. Estimating Shear Velocity and Roughness Length from Velocity Profiles. Water Resources Research, 28(8), 2155-2158.

Biron, P.M., Lane, S.N., Roy, A.G., Bradbrook, K.F., and Richards, K.S., 1998. Sensitivity of bed shear stress estimated from vertical velocity profiles: the problem of sampling resolution. Earth Surface Processes and Landforms 23 (2), 133-139.

Black, K.S., 1998. Suspended Sediment Dynamics and Bed Erosion in the High Shore Mudflat Region of the Humber Estuary, UK. Marine Pollution Bulletin, 37(3-7), 122-133. 
1 Bricker, J.D., Inagaki, S. and Manismith, S.G., 2005. Bed Drag Coefficient Variability under Wind Waves in a Tidal Estuary. Journal of Hydraulic Engineering, ASCE, 131(6), 497508.

Cheng, R.T., Ling, C.H., Gartner, J.W. and Wang, P.F., 1999. Estimates of bottom roughness length and bottom shear stress in South San Francisco Bay, California. Journal of Geophysical Research, 104(C4), 7715-7728.

Cox, M. and Moss, A., 1999. Nerang River, Tallebudgera, Currumbin and Coombabah Creeks: Water Quality Report 1999. Brisbane, Queensland Environmental Protection Agency, 26p.

Crowe, C.T., Elger, D.F. and Roberson, J.A., 2005. Engineering Fluid Mechanics, $8^{\text {th }}$ Ed., John Wiley \& Sons Inc., USA, 656p.

DHI, 2002. Mud Transport Module User Guide, MIKE21 MT, DHI software, DHI Water and Environment, Copenhagen, Denmark, 110p.

Douglas, J.F, Gasiorek, J.M and Swaffield, J.A, 1986. Fluid mechanics. Second Ed., Longman Singapore Publishers Pty Ltd, Singapore, 746p.

Dunn, R.J.K., Ali, A., Lemckert, C.J., Teasdale, P.R., and Welsh, D.T., 2007. Short-term variability of physico-chemical parameters and the estimated transport of filterable nutrients and chlorophyll- $a$ in the urbanised Coombabah Lake and Coombabah Creek system, southern Moreton Bay, Australia. Journal of Coastal Research, SI 50, 1062-1068.

Dyer, K.R., 1986. Coastal and Estuarine Sediment Dynamics, vol. xv, Wiley, Chichester, 342p.

Feddersen, F., Trowbridge, J.H. and Williams III, A.J., 2007. Vertical Structure of Dissipation in the Nearshore. Journal of Physical Oceanography, 37, 1764-1777.

Finelli, C.M., Hart, D.D. and Fonseca, D.M., 1999. Evaluating the spatial resolution of an Acoustic Doppler Velocimeter and the consequences for measuring near-bed flows. Limnology and Oceanography 44(7), 1793-1801.

Galperin, B., Kantha, L.H., Hassid, S. and Rosati, A., 1988. A quasi-equilibrium turbulent energy model for geophysical flows. Journal of the Atmospheric Sciences, 45(1), 55-62. 
1 Garcia, C.M., Jackson, P.R and Garcia, M.H., 2006. Confidence intervals in the determination of turbulence parameters. Experiments in Fluids, 40, 514-522.

3 Granger, R.A., 1985. Fluid Mechanics. Holt, Rinehart and Winston, Tokyo, Japan, 884p.

4 Grant, W.D. and Madsen, O.S., 1986. The continental-shelf bottom boundary layer. Annual 5 Review of Fluid Mechanics, 18, 265-305.

6 Gross, T.F. and Nowell, A.R.M., 1983. Mean flow and turbulence scaling in a tidal boundary 7 layer. Continental Shelf Research, 2, 109-126. South San Fransisco Bay. Journal of Hydraulic Engineering, ASCE, 125(11), 1199-1209.

HydroQual, 2002. User Manual, A Primer for ECOMSED, HydroQual, Inc., Mahwah, N.J. 07430, USA, 188p.

Jing, L. and Ridd, P.V., 1996. Wave-current bottom shear stresses and sediment resuspension in Cleveland Bay, Australia. Coastal Engineering, 29, 169-186.

Kabir, M.R. and Torfs, H., 1992. Comparison of different methods to calculate bed shear-stress. Water Science and Technology, 25(8), 131-140.

Ke, X.K., Collin, M.B., Poulos, S.E., 1994. Velocity structure and sea bed roughness associated with intertidal (sand and mud) flats and saltmarshes of the Wash, UK. Journal of Coastal Research 10, 702-715.

Kim, S.C., Friedrichs, C.T., Maa, J.P.Y., and Wright, L.D., 2000. Estimating bottom stress in tidal boundary layer from Acoustic Doppler Velocimeter data. Journal of Hydraulic Engineering, ASCE, 126(6), 399-406.

Klen, T., 2006. Estuaries, An Introduction to Marine Biology and Oceanography, $<$ http://darter.ocps.net/classroom/klenk/Festuary.htm> (August 22, 2006) 
1 Lee, S.Y., Connolly, R.M., Dale, P.E.R., Dunn, R.J.K., Knight, J.M., Lemckert, C.J., McKinnon, S., Powell, B., Teasdale, P.R., Welsh, D.T. and Young, R., 2006. Impact of urbanisation on coastal wetlands: a case study of Coombabah Lake, South-east Queensland. Brisbane, Technical Report No. 54, CRC for Coastal Zone, Estuary and Waterway Management, 219 p.

Mathisen, P.P., and Madsen O.S., 1996. Waves and currents over a fixed rippled bed 2. Bottom and apparent roughness experienced by currents in the presence of waves, Journal of Geophysical Research, 101(C7), 16,543-16,550.

Nakagawa, H. and Nezu, I., 1975. Turbulence in open channel flow over smooth and rough beds. Proceedings, Japan Society of Civil Engineers, 241, 155-168.

Nikora, V.I. and Goring, D.G., 1998. ADV measurements of turbulence: can we improve their interpretation? Journal of Hydraulic Engineering, ASCE, 124(6), 630-634.

Nortek, 2004. User Manual, Nortek Vector Current Meter. Nortek AS, Vangkroken 2, NO-1351 Rud, Norway, 84p.

Osborne, P.D. and Boak, E.H., 1999. Sediment suspension and morphological response under vessel generated wave groups: Torpedo Bay, Aukland, New Zealand. Journal of Coastal Research, 15(2), 388-398.

Pope, N.D., Widdows, J. and Brinsley, M.D., 2006. Estimation of bed shear stress using the turbulent kinetic energy approach - A comparison of annular flume and field data. Continental Shelf Research, 26, 959-970.

Prandtl, L., 1926. Uber die Ausgebildete Turbulenz. Proceedings of 2nd International Conference on Applied Mechanics, Zurich, 62-75.

Sherwood, C.R., Lacy, J.R. and Voulgaris, G., 2006. Shear velocity estimates on the inner shelf off Grays Harbor, Washington, USA. Continental Shelf Research, 26, 1995-2018.

Soulsby, R.L., 1983. The bottom boundary layer of shelf seas. In: Johns, B. (Ed.), Physical Oceanography of Coastal and Shelf Seas. Elsevier, Amsterdam, 189-266. 
1 Soulsby, R.L. and Dyer, K.R., 1981. The form of the near-bed velocity profile in a tidally accelerating flow. Journal of Geophysical Research-Oceans and Atmospheres, 86 (NC9), 8067-8074.

Stapleton, K.R. and Huntley, D.A., 1995. Seabed stress determinations using the inertial dissipation method and the turbulent kinetic energy method. Earth Surface Processes and Landforms, 20(9), 807-815.

Stips, A., Prandke, H. and Neumann, T., 1998. The structure and dynamics of the Bottom Boundary Layer in shallow sea areas without tidal influence: an experimental approach. Progress in Oceanography, 41, 383-453.

Tennekes, H., and Lumley, J.L., 1972. A first course in turbulence. MIT Press, Cambridge, Massachusetts, USA.

Thomsen, L., 1999. Processes in the benthic boundary layer at continental margins and their implication for the benthic carbon cycle. Journal of Sea Research, 41, 73-86.

Thompson, C.E.L., Amos, C.L., Jones, T.E.R., and Chaplin, J., 2003. The manifestation of fluidtransmitted bed shear stress in a smooth annular flume - a comparison of methods. Journal of Coastal Research, 19(4), 1094-1103.

Wilcock, P.R., 1996. Estimating local bed shear stress from velocity observations. Water Resources Research, 32(11), 3361-3366.

Wilkinson, R.H., 1986. Variation of Roughness Length of a Mobile Sand Bed in a Tidal Flow. Geo-marine Letters, 5, 231-239.

You, Z.J., 2005. Estimation of bed roughness from mean velocities measured at two levels near the seabed. Continental Shelf Research, 25, 1043-1051. 


\section{Figure captions}

Fig. 1: Typical velocity and shear stress distribution within different flow regions (layer thickness is not to scale) of a turbulent bottom boundary layer

Fig. 2: New traversing system

Fig. 3: Schematic set-up of Altimeter and ADV probe

Fig. 4: Location map of the study site, Coombabah Creek and its adjacent estuaries (adapted from Benfer et al., 2007)

Fig. 5: Sample of measured and fitted velocity profiles: (a) stationary ADV; and (b) moving ADV

Fig. 6: Time series of measured and estimated parameters: (a) tidal level; (b) mean velocity; (c) bed shear stress; (d) roughness height; and (e) drag coefficient

Fig. 7: Sample profiles of shear stress: (a) turbulent shear stress estimated by Reynolds stress and TKE methods; and (b) bed shear stress estimated by ID method using dissipation rates at different heights and the same by LP method; (turbulence within the shaded layer could not be measured due to ADV limitations) 


\section{$\underline{\text { Tables }}$}

Table 1: Bed shear stresses $\left(\mathrm{N} / \mathrm{m}^{2}\right)$ estimated by various methods

\begin{tabular}{ccccc}
\hline Profile & LP & Reynolds & TKE & ID \\
& & stress & & \\
\hline 1 & 0.44 & 0.55 & 0.39 & 0.25 \\
2 & 0.47 & 0.28 & 0.47 & 0.36 \\
3 & 0.56 & 0.60 & 0.56 & 0.45 \\
4 & 0.56 & 0.37 & 0.48 & 0.51 \\
5 & 0.50 & 0.45 & 0.36 & 0.33 \\
6 & 0.43 & 0.48 & 0.61 & 0.44 \\
Mean & 0.49 & 0.46 & 0.48 & 0.39 \\
Std & 0.06 & 0.12 & 0.10 & 0.09 \\
\hline
\end{tabular}




\section{Figures}

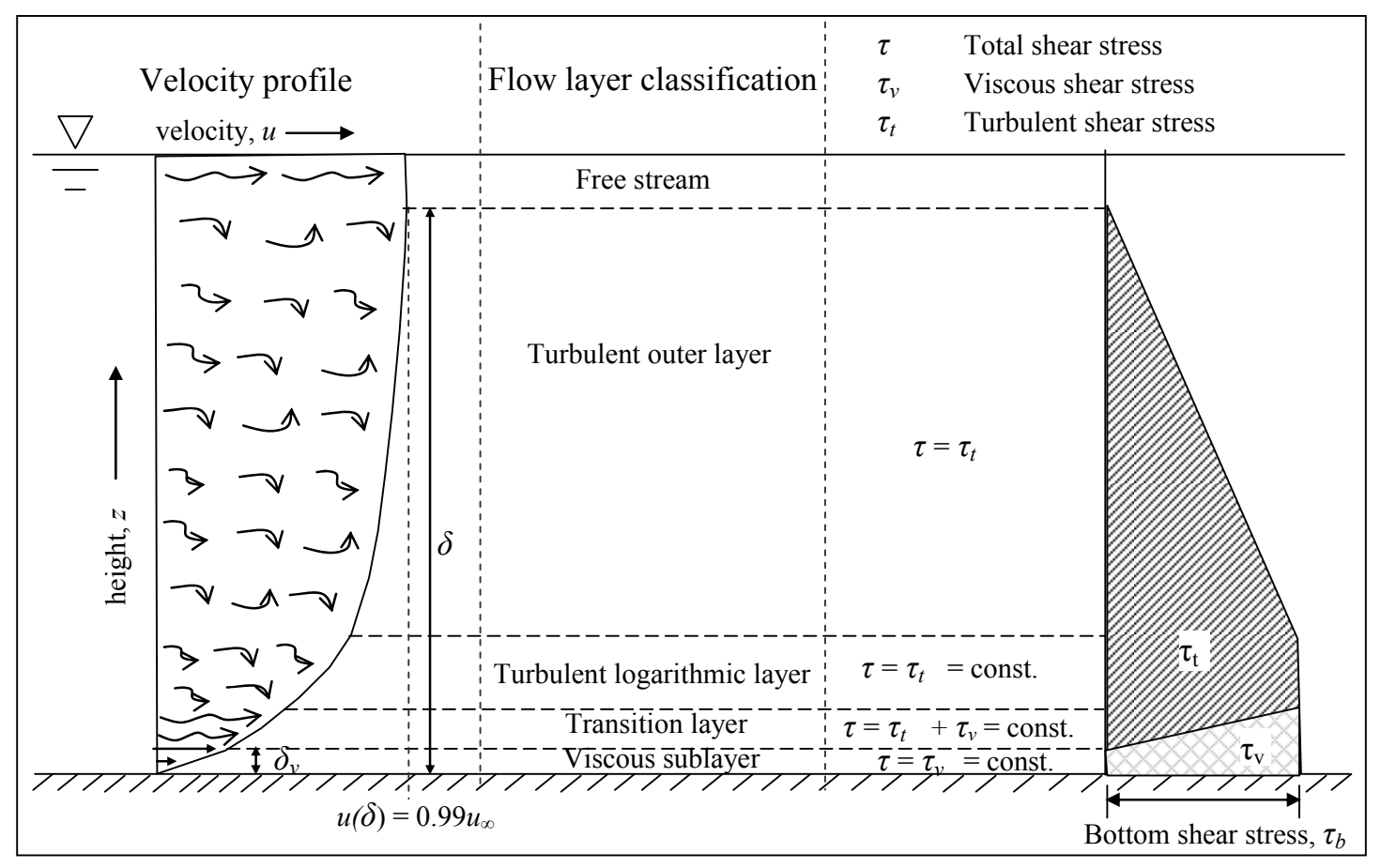

Fig. 1

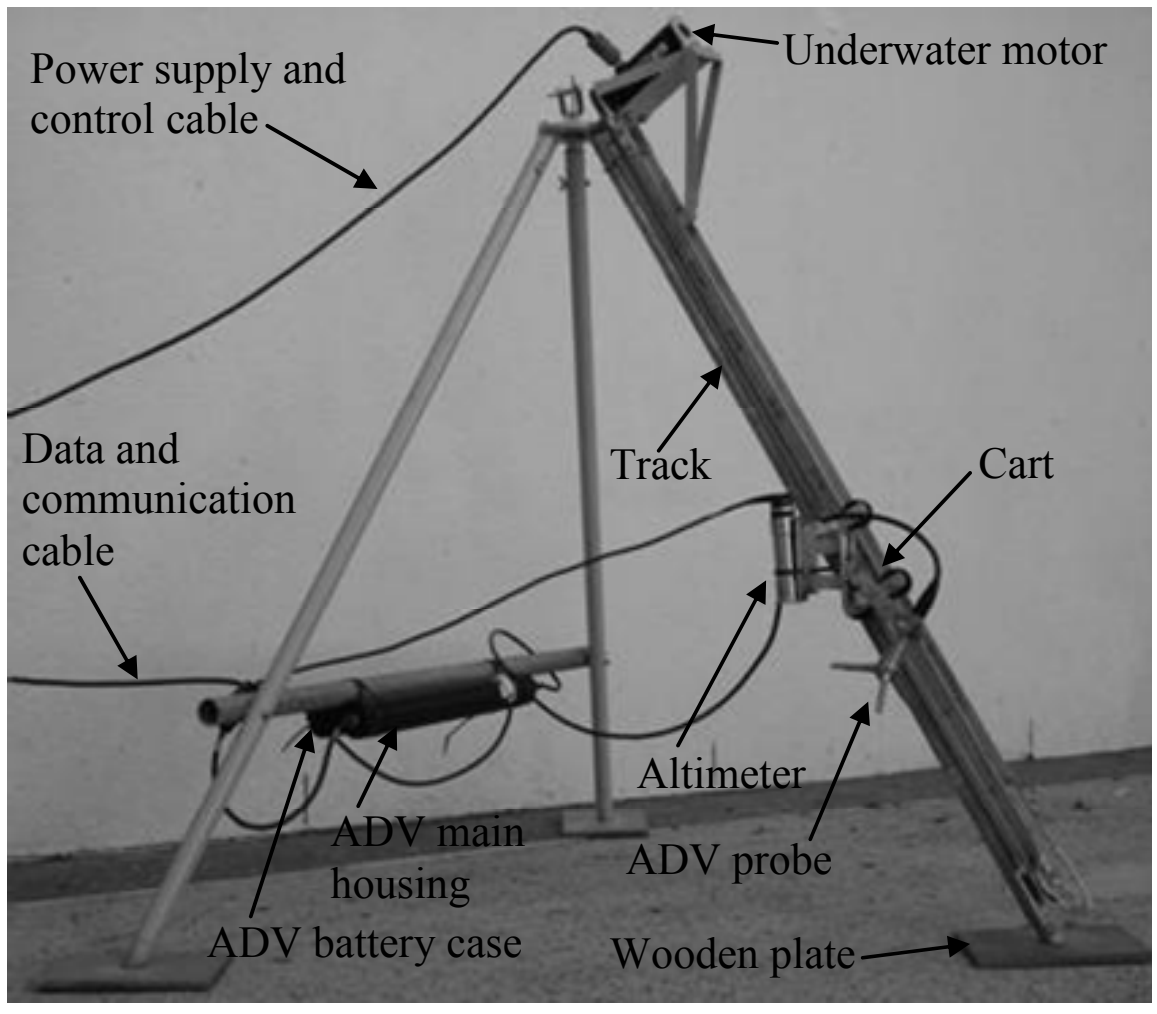

Fig. 2 


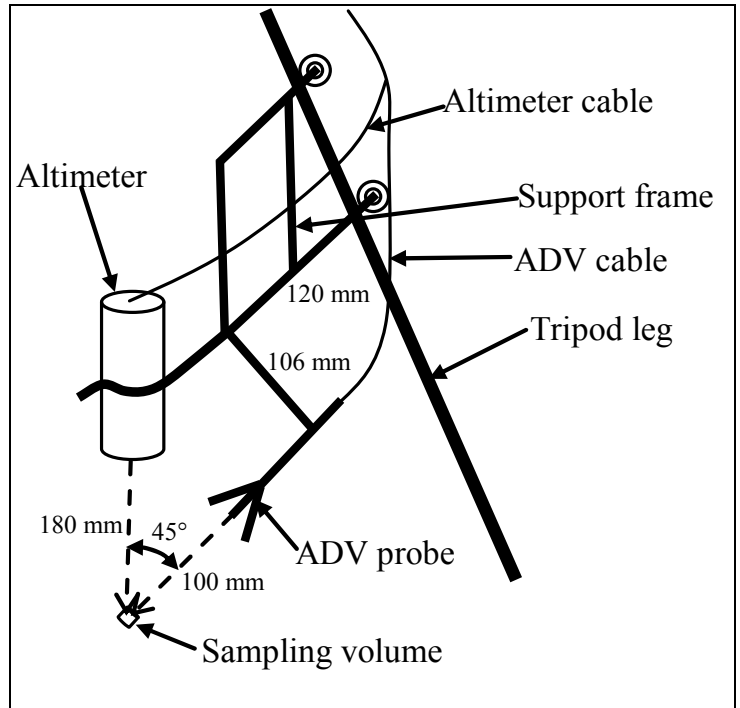

Fig. 3

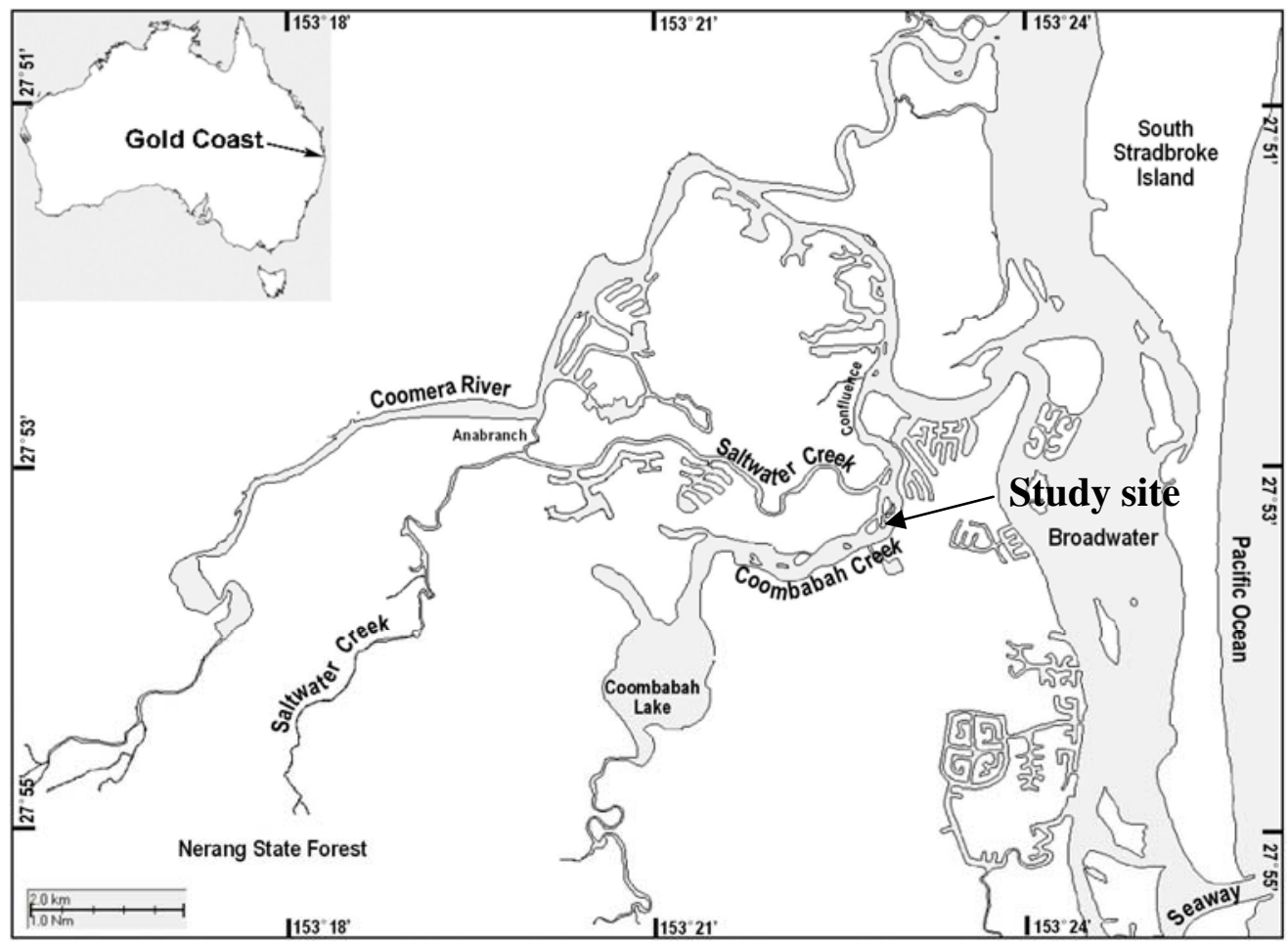

Fig. 4 

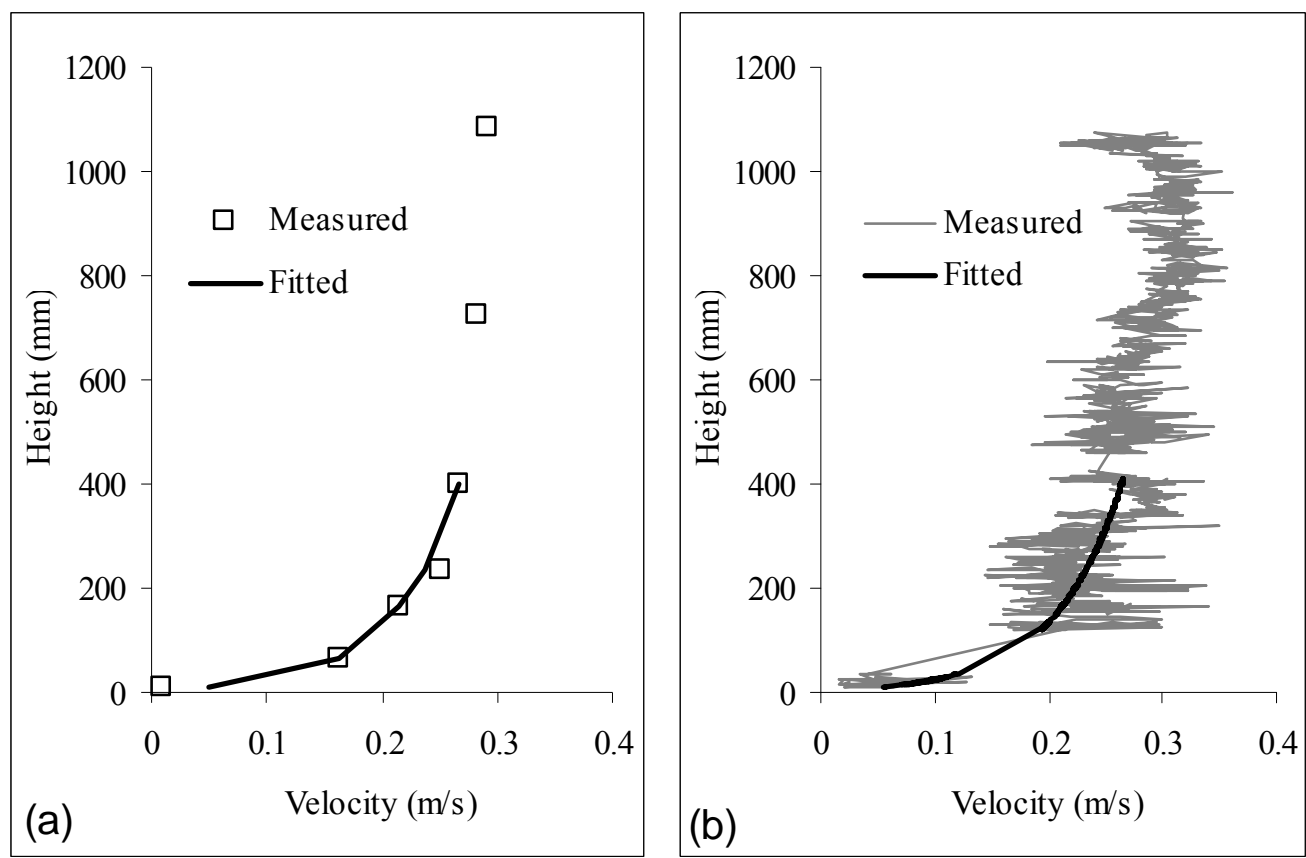

Fig. 5
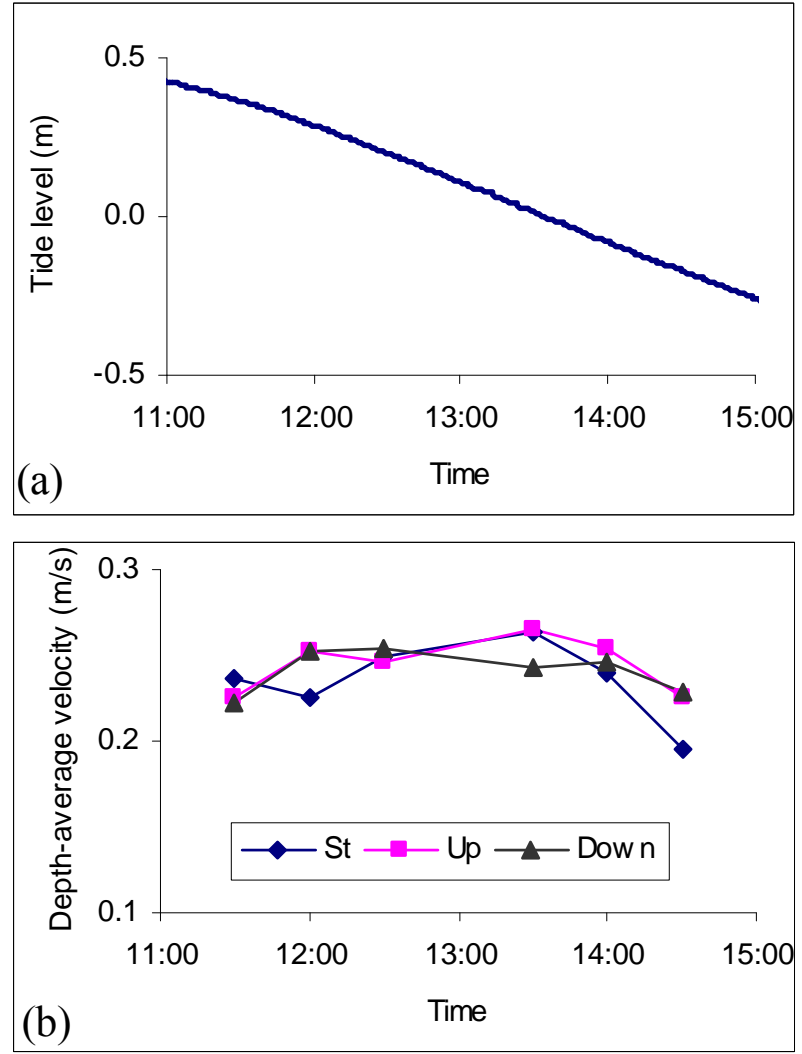

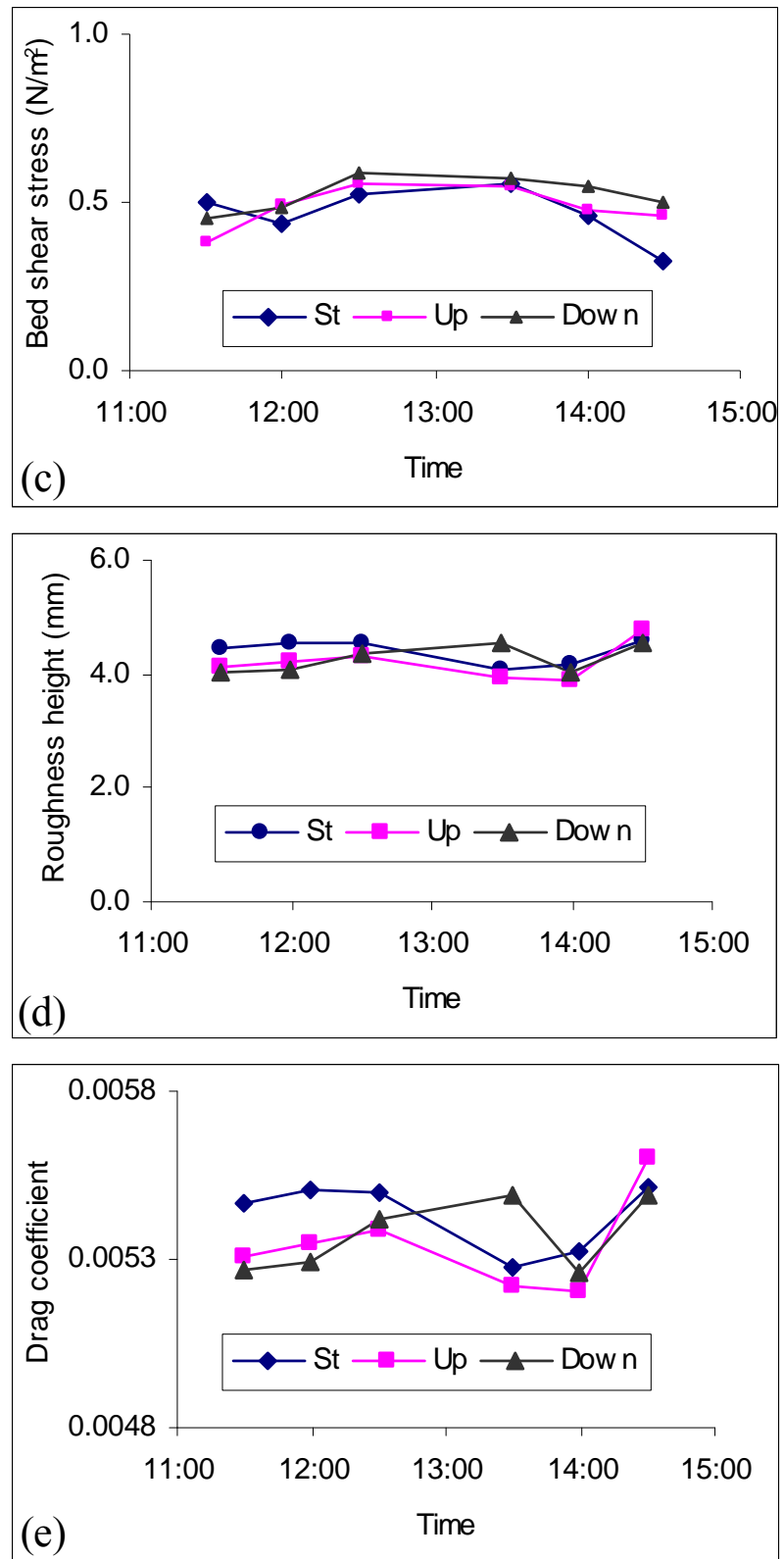

Fig. 6 

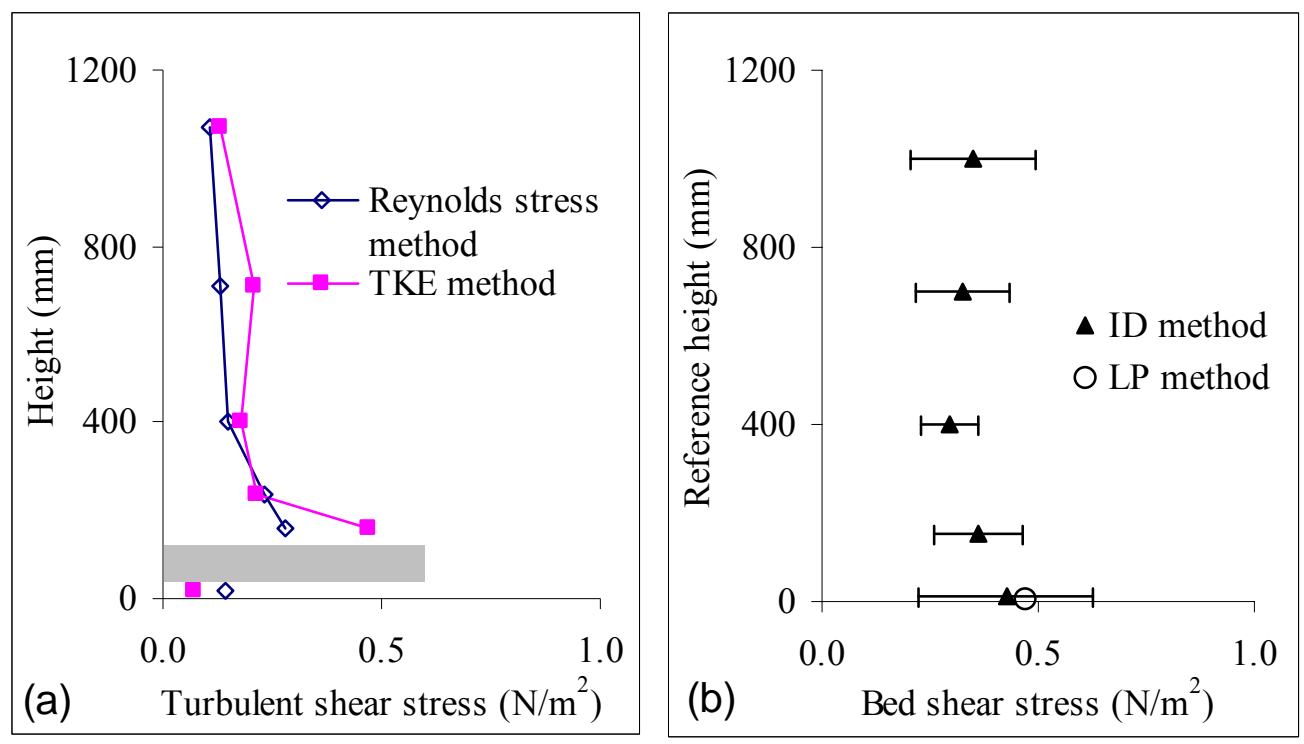

Fig. 7 